University of Nebraska - Lincoln

DigitalCommons@University of Nebraska - Lincoln

July 1987

\title{
Participation and Independence of Consumers in a Health Systems Agency
}

\author{
Keith J. Mueller \\ University of Nebraska Medical Center, kmueller@unmc.edu \\ John C. Comer \\ University of Nebraska-Lincoln, jcomer1@unl.edu
}

Follow this and additional works at: https://digitalcommons.unl.edu/poliscifacpub

Part of the Political Science Commons

Mueller, Keith J. and Comer, John C., "Participation and Independence of Consumers in a Health Systems Agency" (1987). Faculty Publications: Political Science. 1.

https://digitalcommons.unl.edu/poliscifacpub/1

This Article is brought to you for free and open access by the Political Science, Department of at DigitalCommons@University of Nebraska - Lincoln. It has been accepted for inclusion in Faculty Publications: Political Science by an authorized administrator of DigitalCommons@University of Nebraska - Lincoln. 


\section{Participation and Independence of Consumers in a Health Systems Agency*}

\author{
Keith J. Mueller and John C. Comer \\ University of Nebraska-Lincoln
}

\begin{abstract}
Health Systems Agencies (HSAs) were mandated to include representation of the community, broadly conceived. The implicit intention of the law was to include consumers as important and co-equal participants with providers in health planning. This paper is an examination of consumer participation in one HSA. Contrary to expectations derived from the literature, !citizens in this HSA exercised independent judgment regarding the major issue to confront them. We conclude this was a function of the following: talents and skills of the consumer members; natural interest in health care policy by consumer board members, sympathetic and supportive provider board members; and the homogenous character of the population in the region served.
\end{abstract}

" Published in International Journal of Public Administration 9:3 (1987), pp. 229-243. Copyright $\odot 1987$ by Marcel Dekker, Inc. Used by permission.
A $s$ desirable as participation on the part of citizens in the decisions that effect them is, it is difficult in practice to bring about. Even where mechanisms for citizen participation are set up for this expressed purpose, the results typically fall short. This has been particularly true in the area of health planning, where Health Systems Agencies (HSAs) were to be the instrument for citizen participation.

While the continued operation of HSAs is uncertain-the Reagan Administration has eliminated federal funding many of them are currently still in place. Only five states have actually abolished regional HSAs (7). However, health planning in the future may well include HSAs or something like them (7). In any case, it is quite likely that health planning will continue to be a major policy emphasis and that citizens, as consumers, will be involved in it in some way, even if it is only through local general purpose units of government. Therefore, we need to continue with research on the experience of citizens in health planning activities. In this paper, we review the experience of consumer members in health planning in one planning agency. Our thesis is that in at least one HSA, citizen participation succeeded to the degree that the consumer members on the HSA governing board were able to exercise judgments independent of provider members on specific issues. In addition to documenting this, the analysis explores some factors that might account for it. Hopefully the research can serve as a basis for more broadly based inquiries into the factors that contribute to the success of citizen participation in health planning.

Data come from personal interviews with and a survey of selected board members, minutes of SeNHSA board and committee meetings, and interviews with HSA staff and others involved with the HSA concerning the major issue to come before it, the pro- 
posed expansion of a major hospital. While comments apply generally to the SeNHSA's governing board, much of the analysis will deal with this issue.

\section{Theoretical Issues}

If citizen participation in the decisions that effect them means citizen power, as Sherry Arnstein (2) maintains, no one should be surprised at the difficulty, well documented in the literature, in bringing it about. Power is not something one group can have more of, unless, of course, another group has less. As power is quite obviously instrumental in achieving other goals, no group is likely to relinquish it willingly.

Health planning through HSAs was, and it is, an experiment in citizen participation, where on the surface at least, citizens expanded their power at the expense of health care providers (doctors and hospitals) which have traditionally enjoyed a monopoly of power in the field. In terms of Arnstein's ladder of citizen participation, HSAs permitted citizens, if not control, what she refers to as delegated power, a situation where citizens have a clear majority of seats on decision making boards and some specified power. This is to be contrasted with other lower forms of citizen participation which are labeled tokenism and nonparticipation. Here, the traditional power holders remain in control.

While HSAs presented a genuine opportunity for citizens to exercise power, research on the operation of HSAs shows providers basically in control. A number of factors have been suggested to explain provider dominance (6). First, it has generally been observed that consumer representatives on HSA boards lack knowledge of health care and health planning issues, leaving them to decide issues on the basis of information provided by professionals $(13,6)$, and, in general, in a way professions prefer (10).

Second, many consumers are unwilling to get involved or exercise their prerogatives when they do become involved. Most consumers of health care have been socialized to believe that health policy is something to be left to professionals $(9,3)$. Those consumers willing to remain a part of the process often defer to the preferences of providers (1).

Third, providers often are unwilling to share responsibility, undermining any meaningful role that consumers might play (8). Even staff with responsibility to upgrade the capacity of consumer board members in health planning matters may view consumer participation as an unwelcome intrusion (13).

Fourth, consumers also often lack specific ties to the community or organizations within the community which limit the extent to which they will challenge the well organized and often cohesive health care establishment $(14,12)$. While providers are backed and spurred on by the institutions they represent, consumers are loose, unattached individuals who appear to be going it alone.

Fifth, there is also the problem of discerning just what the role of the consumer member is supposed to be, planner or advocate of community interests (4). Inability to resolve these mutually exclusive roles often leads consumers to follow the line of least resistance, acquiescing to the demands of providers.

Provider dominance need not, however, be the inevitable outcome on HSA boards. While research has described the activities on the part of citizens in $\operatorname{HSAs}(5,11)$, there has been little or no research focusing on decision making and the role played by consumer members in it. An assessment of consumer activities requires an examination of the decision making proc- 
ess. The research that follows attempts this with the most significant issue to come before the Southeast Nebraska Health Systems Agency.

\section{Background Information}

SeNHSA encompasses a seventeen county region and includes a major urban area, the City of Lincoln (approximate population 170,000). Its board of directors numbers 33,17 of which are consumers. Consumer members were recommended by local civic leaders, who were free to nominate themselves, and selected by the county commissioners in each county. In Lincoln, Lancaster County, selection was by the city-county common, the city council and county commission combined. Each county was entitled to select a number of directors equal to the county's proportion of population in the 17 county region. Selection was consistent with federal regulations requiring representation of demographic groups.

In October 1980, one of Lincoln's three major hospitals, Bryan Memorial, submitted a plan to expand its facilities to provide more and presumably better cardiac, general surgical, and emergency treatment. The hospital estimated the cost at $\$ 55$ million, $\$ 35$ million to be financed from the sale of revenue bonds. The proposed expansion included facilities to train nurses, facilities for rehabilitation including a track and a swimming pool, hotel type facilities for the families of patients, additional parking space, and an expanded physical plant for supplying energy. While nobody questioned the need for some improvement in the oldest hospital in the community, debate concerned the extent or degree of improvement.

SeNHSA reviewed the proposal and recommended the state issue a certificate of need. SeNHSA*s Project Review Committee was principally involved in evaluating the proposal. Its deliberations lasted until April, 1981.

\section{INDEPENDENCE OF CONSUMER MEMBERS}

Our thesis is that the consumer members of SeNHSA's governing board exercised independent judgment. By independence, we do not mean that consumer members were uninfluenced by others involved in the process (providers and staff), only that they were not led by or dictated to by others. A decision contrary to the preferences of providers and staff would, of course, be clear evidence of independence. In addition to decision outcomes, independence can also be determined from the assessments of those involved in the process. When reconstructing decision-making processes in search of motivations for actions, perceptions by those involved are imperfect but good proximate indicators. In the following analysis, both decisions as well as assessments of those involved are examined.

\section{Independence from Providers}

An important test of the independence of consumers is their independence from providers. If consumers merely follow the lead of provider members, they have no effective voice. To assess the influence of consumer members of SeNHSA several board members, HSA staff, and others involved with the Bryan expansion were asked in a focused interview format if consumer members were active as independent spokesmen in the deliberations of the board.

The evidence suggests that they were. While some expressed concern that consumer board members followed the lead of the providers on the board and had no conception that providers 
might do something not in the consumer's interest, most of those interviewed expressed sentiments that contradicted this. For example, most pointed out that the consumer members on the board were very vocal, more so than providers. Consumer members were so vocal that one provider member claimed that the board was slanted toward consumers. This vocalness apparently reflected disagreement, as this same person recalled several recommendations from provider members that were ignored by the consumers on the board. Another board member referred to the "very vociferous consumer members." This tendency to speak out resulted in several consumer members being sought out by the press for interviews.

A non board member but a person who was heavily involved in the Bryan issue identified some consumer members as "super consumers." He elaborated that they were well trained and educated and able to hold their own in discussions. He indicated that they were willing to take a position and argue persuasively for it. Likewise, a staff member found the consumers on the board to be persuasive and willing to take a position. Another interviewee identified the exchanges between consumer and provider members as informative. Providers, he noted, were forced to defend their policies and programs.

Several of those interviewed pointed out that some consumer members emerged as leaders on the board. One, in particular, was identified as very influential. One board member reflected that in a small group individuals with special training and skills are accorded respect and some degree of deference. Two consumer members, one with a background in economics and the other in business were, thus, able to establish themselves as leaders and play a dominant role in proceedings.
Themes which emerged from the focused interviews were also evident in responses to questionnaire items submitted to each member of the governing board. Of the 31 members, nine were returned from the 17 consumer members and seven from the provider members. Respondents were asked to evaluate the following statements: providers dominate policy and planning, consumers defer to providers, and consumer members play strong leadership roles in the agency. With respect to the consumer members, four disagreed with the first statement and one strongly disagreed. Three of these served on the Project Review Committee and may have been in the best position to judge this. Three strongly agreed with the statement and one failed to respond. With respect to the item, consumers defer to providers, three disagreed, two strongly, and three agreed. again, one failed to respond. Four agreed with the statement that consumer board members play strong leadership roles in the agency; two failed to respond, and three disagreed. Among providers, one strongly agreed and another agreed that providers dominate, however, two strongly disagreed and three disagreed. With respect to consumer deference, four disagreed and two strongly disagreed. Regarding consumer board members play strong leadership roles in the agency, two strongly agreed. Three others agreed, and one disagreed. These responses do not convey an image of consumer acquiescence and passivity but of participation and quality. They also indicate some consumer leadership on the board. While we recognize the limitations of assessments on the part of those involved, these data, if they do not allow us to confirm the thesis of consumer independence, certainly permit us to reject the idea of provider dominance.

There remains, however, the question of outcome. How did the HSA treat the proposal? We have already pointed out that the 
board recommended approval of the certificate of need, but there is more to it than this. For example, it was in response to consumer initiatives that Bryan officials modified their original proposal. Following the first public hearing several members of the Project Review Committee listed several items of concern regarding the hospital's proposal. One of the committees concerns was whether services at the hospital would duplicate those offered by a professional care center nearby. Subsequently, the proposal was rewritten to eliminate possible duplication At one point in the proceedings, the entire proposal was withdrawn in order to eliminate items objected by the Project Review Committee. For example, a proposed kitchen (part of rehabilitation training), swimming pool and track (both included in rehabilitation facilities), were deleted. Constraints were placed on financing as well. Interest on the revenue bonds were not to exceed a specified level. This has remained a problem for Bryan Hospital. To date, the interest ceiling has made it very difficult to sell the bonds. Currently, the hospital is appealing to a gubernatorial appointed board to have this limitation lifted.

It is clear that the Bryan proposal did not move through the review process quickly or smoothly. It is also clear that changes were brought about as a result of review and that these were related to the cost cutting concerns of the HSA.

All of this, however, does not mean that the best interests of the citizens of the community were served. While this may be true, some factors need to be considered. First, consumers on the board were not elected, and did not represent well defined constituencies. They were selected because they were part of or thought to represent particular demographic classifications. Second, the community at large in southeast Nebraska or parts therein are, to be sure, not organized around or exercised by health care issues. We can say, however, that the board, if nothing else, recognized their role of checking health care costs. To the extent that this served the community's interest, the community interest was represented.

Although their final action was to recommend approval of the plan submitted by Bryan, the evidence suggests that the consumer members acted independently of providers both on and off the board. Nor was the process dominated by providers* information or as a result of their expertise.

\section{Independence from Staff}

HSA staff are generally professional health care planners. Their function, among other things, is to train and educate board members regarding general issues in health care planning as well as inform them regarding the merits from the perspective of the community's overall plan, of specific provider proposals. As a result, staff can exercise considerable influence over board members, particularly consumer representatives, who may be, to a large extent, unfamiliar and uneducated with respect to health care issues. The opportunity is present, to be sure, for staff to manipulate board members. This need not be conspiratorial or even conscious. We can assess the role of staff in this regard by examining how board members responded to staff recommendations. Rather than isolating consumer members, the analysis in this section will examine the relationship between staff and the board in general. In all of the specifics discussed, consumers and providers acted in unison vis a vis staff. Did they accept, modify or reject them? While acceptance will not necessarily mean manipulation, modification or rejection will certainly be evidence for the board's independence from the staff. We can 
also explore how the board related to the staff as revealed in interview materials.

With respect to the Bryan Proposal, the staff recommended to the Project Review Committee that the HSA accepted the proposal, subject to the following conditions:

1. that hospital authority bonds to finance the project be at a ten percent rate of interest

2. that the authority board responsible for issuing bonds encompass the entire county and be available to all health care facilities in the county.

3. that the hospital cooperate with the county medical society and the HSA in health planning in the future and consider consolidating with other providers certain hospital services

4. that 1540 square feet of space be removed from a center of health education

5. that "ten motel type rooms" be eliminated from a center for health education

6. that space allotted to health education programs in a center for health education be reduced

7. that upgrading of CAT scanner software be eliminated

8. that a thirty bed pod be eliminated and a psychiatric unit not be renovated.

Those eight recommendations can serve as a test of the board's independence. Of the eight, the Project Review Committee accepted only numbers one and three, and modified number one by eliminating the ten percent figure in favor of general language which would allow the hospital to fund the project at a higher level of interest as long as hospital charges to patients would not increase beyond the inflation rate. One can, of course, claim that the conditions were minor compared to the overall proposal which the staff recommended the board approve and which the board did approve. Would not this be evidence that the board followed the lead of the staff? However, there was little doubt that Bryan needed to expand. The point of contention was the dimensions of the expansion, and it is this that the issues raised by the staff addressed. One might also claim that the conditions raised by the staff were not particularly important to the staff. Comments by the staff, however, believe this interpretation. Staff felt, at least prior to the final session of the Review Committee, the issues to be quite significant. While one has to be cautious in drawing conclusions from a single case, it appears that we are left with the conclusion that the board acted contrary to the wishes of the staff.

The conclusion is the same if one examines interview responses of the board regarding their independence of staff. There is some evidence that the board viewed their relationship with staff in terms of a division between policy and administration, i.e., the staff provided information but did not make policy. SeNHSA may be unique in that the staff was generally at odds with providers. This put the consumer members of the board in the enviable position of receiving conflicting information. This enhanced their ability to be independent. Responses in our interview sessions indicate that consumers used this advantage to exercise independent judgment.

\section{CONCLUSION}

While it is clear to us that the consumer members of the board acted independent of providers and staff, another research question concerns the basis for decision. All but one 
member of the board voted for the proposal. The lone dissenter feared increasing costs would follow acceptance. For those who supported the proposal, two factors stand out. First, the project was needed. The hospital is 50 years old, and by most standards badly in need of renovation. One board member expressed reservations about the total cost, but voted for the proposal because of what he perceived was a "very serious facilities problem." After viewing a three hour presentation given by Bryan officials and examining Bryan facilities first hand, the need was apparent. Second, there was little opposition to the proposal. In the early stages, a few residents close to Bryan feared that the residential character of the neighborhood would be jeopardized. There was also an official from Lincoln General Hospital, (a competitor hospital), who expressed concern primarily with respect to cost implications. Both of these concerns seem to have faded by April, or at least, they were not brought up again. There is some speculation that pressure from the medical community helped quiet Lincoln General. Third, there was overwhelming support to move forward with the proposal. Not only was the medical community strongly supportive, but many patients and former patients of Bryan Hospital testified in favor of the proposal.

Thus, while the project was approved, it was not the result of providers overwhelming consumers or consumers backing off. Approval followed close scrutiny of the proposal by the Project Review Committee, where important questions were raised and dealt with, and was based on a clearly demonstrated need.

Research has shown that consumer participation in health planning through HSAs has not been very successful. The general conclusion is that consumers are ill equipped to participate on an equal footing with providers. The result has been provid- ers dominating in health planning much like they have in the past. This however, was not the case in SeNHSA. The pattern observed for SeNHSA raises doubts about the generality of the above conclusion but more importantly holds out the prospect for the success of consumer involvement in health planning.

\section{DISCUSSION}

Why did consumer participation work better in SeNHSA? There are four factors that can be pointed to and serve as a basis for future research:

1. The talents and skills of the consumer members;

2. Consumer members had interest in health care policy before joining the agency;

3. Provider members were sympathetic and supportive of consumer involvement in health planning; and

4. the homogenous character of the population in the region covered by SeNHSA.

The consumer members on the board were a talented and skillful lot. They were articulate and analytical. Several had professional degrees. They were confident and not the type to be intimidated by providers. Many had an interest or experience in health care that predated their appointment to the board. Recruitment of such types was possible, we believe, because of the nature of the selection process. An initial pool of potential appointees were suggested by civic leaders. Appointments to the board were then made by elected public officials. While community representation in terms of demographic characteristics may have suffered, it was possible to get persons who were willing to serve and capable of doing an effective job. A tradeoff must necessarily exist between achieving the kind of representation 
envisioned in the law and effective consumer participation. One way to increase the prospects of the latter is to involve community leaders. While this typically will mean that some segments of the community, the poorer and less educated, might not be a part of the decision making process, it does not mean that their interests will be ignored. Requirements for independent, effective consumer participation are best met if they are the focus of the selection process. By having consumer represented by effective spokesmen, all groups have a better change to be represented.

SeNHSA also benefited from providers that did not view citizen participation as an unwelcome intrusion. They encouraged and welcomed consumer input. Research suggests this pattern may be unique.

Finally, the 17 county region covered by SeNHSA does not have the diversity of people or interests that characterize many other HSAs. Providers and consumers on the board and in the community are in basic agreement on what constitutes quality health care and how it should be delivered. The Bryan Hospital proposal was consistent with community expectations. The principal concern of most residents regarding health care is access to the best available care, not the costs of the care. Third party payers will in most instances bear most the burdens of increased costs. Bryan officials emphasized that their proposal would improve the quality of care provided. They indicated that the proposal would obviate the need to travel to Minnesota and other places for certain types of care. In sum, officials presented the proposal in a way that made it acceptable to all. This eliminated much potential conflict at the start.

Given the consensus that existed in the community, one might ask, was the HSA necessary? Certainly the expansion would have occurred without it and this would have been consistent with community desires. This, however, ignores the modifications that were made in the proposal, the challenge to providers which made them think through their ideas, and the desirability of having individuals involved in the decisions that effect them. Without HSA, even minor modifications, such as those made in the Bryan proposal, would not have been made.

\section{REFERENCES}

1. Alford, R. R. Health Care Politics: Ideology and Interest Group Barriers to Reform. Chicago: University of Chicago Press, 1975.

2. Arnstein, S. "A Ladder of Citizen Participation." Journal of the American Institute, Planners 35 (July, 1969):216-224.

3. Boulding, K.E. 1981. The Concept of Need for Health Services, in John B. McKinlay, ed. Economics and Health Care. Cambridge: The MIT Press.

4. Browne, B. "Rational Planning; and Responsiveness: The Case of the HSAs" Public Administration Review 41 (July/August, 1981):1437-44.

5. Checkoway, B. 1981. Consumerism in Health Planning Agencies. Committee on Health Planning Goals and Standards, ed. Health Planning in the U.S.: Selected Policy Issues. Washington, D.C.: National Academy Press.

6. Checkoway, B. 1979. Citizens on Local Health Planning Boards: What are the Obstacles? Journal of the Community Development Society 10, (Fall):101-116. 
7. Congressional Quarterly. 1982. Health Planning System Lacks Friends, But Its "Enemies" May Save it From Extinction. Congressional Quarterly 40, (June 5):1335-1338.

8. Ellenburg, D. 1981. Special Interests vs. Citizen Control: Who Owns Planning? in Committee on Health Planning Goals and Standards. Health Planning in the United States: Selected Policy Issues Volume Two. Washington, D. C.: National Academy Press.

9. Lipsky, M. and Lounds, M. "Citizen Participation and Health Care: Problems of Government and Induced Participation." Journal of Health Politics, Policy, and Law 1 (Spring, 1976):85-111.

10. Marmor, T.R. and Marone, J.A. "USA's and the Representation of Consumer Interests: Conceptual Issues and Litigation Problems." Health Law Project Library Bulletin 14 (April, 1979):111-218.

11. Marone, J.A. 1981. Models of Representation: Consumers and the HSAs, in Committee on Health Planning Goals and Standards, ed. Health Planning in the U.S.: Selected Policy Issues Volume Two. Washington, D.C.: National Academy Press.

12. Marone, J.A. and Marmor, T. R. 1981. Representing Consumer Interests: The Case of American Health Planning, in B. Checkoway, ed., Citizens and Health Care: Participation and Planning for Social Change. New York: Pergamon Press.

13. Paap, W.R. "Consumer-Based Boards for Health Centers: Structural Problems in Achieving Effectiveness and Control." American Journal of Public Health 68 June, 1978):578-583.
14. Vladeck, B.C. "Interest Group Representation and the USA's: Health Planning and Political Theory." American Journal of Public Health 67 (January, 1971):23-28. 